\title{
PENGARUH PENAMBAHAN SARI PALA (Myristica fragrans) DAN CENGKEH (Eugenia carryophyllus) TERHADAP TINGKAT KESUKAAN MINUMAN SERBUK BERBASIS LEMON CUI (Citrus microcarpa)
}

\author{
ADDITION EFFECT OF NUTMEG (Myristica fragrans) AND CLOVE \\ (Eugenia carryophyllus) JUICE ON THE LEVEL OF PREFERENCE OF LEMON CUI \\ BASED POWDER (Citrus microcarpa)
}

\author{
Mariati Edam \\ Balai Riset dan Standardisasi Industri Manado \\ Jalan Diponegoro No. 21-23 Manado \\ Telp. (0431) 852395, Fax. (0431) 852396 \\ Pos-el: edam.mariati@gmail.com
}

\begin{abstract}
ABSTRAK
Lemon cui, daging pala dan daun cengkeh mengandung antioksidan yang dapat ditambahkan pada minuman serbuk. Tujuan penelitian ini adalah untuk mendapatkan formula yang paling disukai dari minuman serbuk instan berbasis lemon cui dengan penambahan sari buah pala dan daun cengkeh. Penelitian ini menggunakan Rancangan Acak Lengkap (RAL) dengan perlakuan jenis penambahan sari daging pala dan sari daun cengkeh sebagai antioksidan, sebanyak enam level perlakuan yang dibuat dalam bentuk formulasi sebagai berikut: (A) sukrosa 50\% : sari lemon cui $30 \%$ : air $20 \%$; (B) sukrosa $50 \%$ : sari lemon cui $30 \%$ : sari pala $0 \%$ : sari cengkeh $20 \%$; (C) sukrosa $50 \%$ : sari lemon cui $30 \%$ : sari pala $5 \%$ : sari cengkeh $15 \%$; (D) sukrosa $50 \%$ : sari lemon cui $30 \%$ : sari pala $10 \%$ : sari cengkeh $10 \%$; (E) sukrosa $50 \%$ : sari lemon cui $30 \%$ : sari pala $15 \%$ : sari cengkeh $5 \%$; (F) sukrosa $50 \%$ : sari lemon cui $30 \%$ : sari pala $20 \%$ : sari cengkeh $0 \%$. Hasil penelitian menunjukkan bahwa persentase tingkat kesukaan panelis berdasarkan indikator warna, aroma dan rasa minuman serbuk berbasis lemon cui berkisar 57 $67 \%$, dengan kriteria tingkat kesukaan adalah netral. Hasil uji organoleptik menunjukkan bahwa tingkat kesukaan terhadap warna $(2,76-3,68)$, aroma $(2,70-3,12)$ serta rasa $(2,54-3,24)$ dengan kriteria suka. Berdasarkan hasil penelitian maka diperoleh simpulan bahwa tingkat kesukaan panelis terhadap minuman serbuk instan berbasis lemon cui terbaik adalah formula B.
\end{abstract}

Kata kunci: Cengkeh, lemon cui, minuman serbuk, pala.

\begin{abstract}
Lemon cui, nutmeg meat and clove leaf contain antioxidants which can be added to powder drinks. The purpose of this study was to obtain the most preferred formula of lemon cui based instant powder drinks with the addition of nutmeg and clove leaf juice. This research uses Complete Random Design (CRD) with the treatment of the type of addition of nutmeg and clove leaf juice as antioxidants, as many as six levels of treatment made in the following formulations: (A) sucrose $50 \%$ : lemon cui juice $30 \%$ : water 20\%; (B) sucrose $50 \%$ : lemon cui juice 30\% : nutmeg juice 0\% : clove juice $20 \%$; (C) sucrose $50 \%$ : lemon cui juice 30\% : nutmeg juice 5\% : clove juice 15\%; (D) sucrose 50\% : lemon cui juice 30\% : nutmeg juice $10 \%$ : clove juice 10\%; (E) sucrose 50\% : lemon cui juice 30\% : nutmeg juice 15\% : clove juice $5 \%$; (F) sucrose $50 \%$ : lemon cui juice 30\% : nutmeg juice 20\% : clove juice $0 \%$. The results showed that the percentage of panelists' preference based on indicators of color, odor and taste of lemon cui based powder drinks ranged from 57 to $67 \%$, with preference level criteria being neutral. The organoleptic test results showed that the level of preference for color (2.76-3.68), odor (2.70-3.12) and taste (2.54-3.24) with criteria of like. Based on the results of the study, it was concluded that the panelists' preferred level of the best lemon cui based instant powder drink was formula $B$.
\end{abstract}

Keywords: Cloves, lemon cui, nutmeg, powder drinks.

\section{PENDAHULUAN}

Produk pangan fungsional yang mengandung antioksidan dalam bentuk minuman banyak bermunculan di pasaran. Antioksidan merupakan senyawa penting dalam menjaga kesehatan tubuh karena berfungsi sebagai penangkal radikal bebas dalam tubuh. Dengan mengkonsumsi minuman yang banyak mengandung antioksidan dengan jumlah yang memadai maka dapat meningkatkan daya tahan tubuh sehingga dapat mencegah penyakit degeneratif serta menghambat timbulnya penyakit akibat penuaan sel. Produk pangan 
yang beredar sebagian besar mengandung antioksidan sintetik. Kekhawatiran akan adanya kemungkinan efek samping dari antioksidan sintetik menyebabkan antioksidan alami dapat dijadikan pengganti. Antioksidan alami perlu dikembangkan untuk memperoleh produk antioksidan yang lebih aman. Senyawa antioksidan alami tumbuhan adalah senyawa fenolik atau polifenolik yang dapat berupa golongan flavonoid, tokoferol dan asam-asam polifungsional. Bahan pangan yang berpotensi sebagai antioksidan antara lain lemon cui, buah pala dan cengkeh $^{(1)}$.

Lemon cui (Citrus microcarpa) memiliki nilai gizi tinggi terutama kandungan vitamin $\mathrm{C}$ yang dikenal sebagai antioksidan yang sangat kuat sehingga dapat digunakan sebagai bahan dalam pembuatan minuman. Buah lemon cui berwarna kuning ketika matang dengan diameter 2-3,5 cm dan berkulit tipis. Kulit berwarna hijau ketika masih mentah dan berwarna kekuningan saat sudah matang dan terdapat biji dalam daging lemon cui. Keunggulan lemon cui salah satunya mampu berbuah sepanjang musim $^{(2)}$. Pemanfaatan buah lemon cui yang memiliki nilai gizi serta rasa yang khas sebagai media pemeliharaan kesehatan tubuh dan kulit maka perlu diolah menjadi suatu produk minuman serbuk instan. Minuman serbuk instan merupakan produk dalam bentuk konsentrat atau terpekatkan dengan penghilangan air sehingga mudah larut dan siap dikonsumsi. Proses pembuatan minuman instan secara umum terdiri dari dua tahapan yaitu proses ekstraksi dan proses pengeringan ${ }^{(3)}$.

Guna meningkatkan kadar antioksidan minuman serbuk berbasis lemon cui maka dibutuhkan penambahan bahan yang samasama memiliki antioksidan untuk memperkaya antioksidan baik jenis maupun jumlah yang terkandung pada minuman serbuk berbasis lemon cui. Beberapa tanaman yang berpotensi sebagai antioksidan adalah pala dan cengkeh. Tanaman cengkeh (Eugenia carryophyllus) merupakan tanaman perkebunan yang banyak ditemukan di kawasan timur Indonesia. Komponen utama minyak daun cengkeh adalah eugenol sekitar $80-90 \%$ dan sisanya $10-20 \%$ kariofilin serta seskuiterpen lain. Eugenol termasuk senyawa fenolik sederhana, yaitu mempunyai gugus fungsi hidroksi pada cincin aromatik sebagai antioksidan. Bahan rempah lainnya yang mempunyai potensi sebagai antioksidan adalah buah pala. Pala merupakan tanaman aromatik dan dikenal sebagai tanaman rempah yang memiliki nilai ekonomi dan multi guna karena setiap bagian tanaman dapat dimanfaatkan dalam berbagai industri $^{(4)}$. Minyak atsiri dalam daging buah pala mengandung komponen miristisin dan monoterpen. Miristisin digolongkan dalam flavonol dari senyawa flavonoid yang merupakan senyawa fenolik yang berfungsi sebagai antioksidan ${ }^{(5)}$. Berdasarkan potensi yang dimiliki lemon cui, daging pala dan daun cengkeh maka dapat diolah menjadi minuman serbuk instan yang mengandung antioksidan. Penelitian ini bertujuan untuk menganalisis pengaruh penambahan sari pala (Myristica fragrans) dan cengkeh (Eugenia carryophyllus) terhadap tingkat kesukaan minuman serbuk berbasis lemon cui (Citrus microcarpa).

\section{METODOLOGI PENELITIAN}

\section{Bahan dan Alat}


Bahan yang digunakan dalam penelitian ini adalah lemon cui (Citrus microcarpa), daun cengkeh (Eugenia carryophyllus), daging pala (Myristica fragans), sukrosa, Na-bikarbonat (soda kue).

Alat-alat yang digunakan dalam penelitian ini adalah hot plate, timbangan, gelas piala, baskom, blender, termometer, oven.

\section{Metode Penelitian}

Penelitian ini mengunakan Rancangan Acak Lengkap (RAL) dengan perlakuan jenis penambahan sari daging pala dan sari daun cengkeh sebagai antioksidan sebanyak enam level perlakuan yang dibuat dalam bentuk formulasi sebagai berikut:

A. Sukrosa 50\% : Sari lemon cui 30\%: Air $20 \%$

B. Sukrosa $50 \%$ : Sari lemon cui 30\% : Sari pala $0 \%$ : Sari cengkeh $20 \%$.

C. Sukrosa 50\% : Sari lemon cui 30\% : Sari pala $5 \%$ : Sari cengkeh $15 \%$.

D. Sukrosa $50 \%$ : Sari lemon cui $30 \%$ : Sari pala $10 \%$ : Sari cengkeh $10 \%$.

E. Sukrosa 50\% : Sari lemon cui 30\% : Sari pala $15 \%$ : Sari cengkeh $5 \%$.

F. Sukrosa $50 \%$ : Sari lemon cui $30 \%$ : Sari pala $20 \%$ : Sari cengkeh $0 \%$.

\section{Prosedur Pembuatan}

Sari pala dan daun cengkeh ditambahkan pada sari lemon cui yang telah disiapkan terlebih dahulu (sesuai formulasi). Selanjutnya dinetralkan dengan natrium bikarbonat hingga $\mathrm{pH}$ netral (6,5-7). Setelah itu ditambahkan gula sukrosa dan diaduk dengan sendok kayu. Kemudian dimasak dengan menggunakan suhu $75-80^{\circ} \mathrm{C}$ selama \pm 1 jam dan pada saat pemasakan larutan tersebut diaduk-aduk terus sampai menjadi pekat kemudian diangkat. Sari buah pekat ini didinginkan sambil diaduk terus hingga terbentuk kristal-kristal sari buah. Kristalkristal yang terbentuk dikeringkan lagi selama 3 jam pada suhu $50^{\circ} \mathrm{C}$ kemudian diayak dengan menggunakan ayakan 60 mesh untuk memperoleh ukuran yang seragam dan dikemas.

\section{Parameter Pengujian}

Uji organoleptik yang dilakukan adalah uji kesukaan, panelis diminta untuk memberikan tanggapan tentang tingkat kesukaan atau ketidaksukaan. Pengujian dilakukan untuk mengkaji reaksi panelis terhadap sampel yang diujikan yaitu untuk mengetahui daya terima dari panelis yang dilakukan dengan menggunakan analisis deskriptif persentase. Penelitian ini menggunakan 5 (lima) skala hedonik yang menunjukkan tingkat kesukaan panelis. Pelaksanaan uji dilakukan dengan cara menyajikan produk yang telah diberi kode (menggunakan bilangan acak) dan panelis diminta untuk memberikan penilaian pada score sheet yang telah disediakan dengan skala penilaian yaitu 1 (tidak suka), 2 (kurang suka), 3 (netral), 4 (suka), 5 (sangat suka) ${ }^{(6)}$. Panelis yang dibutuhkan sebanyak 25 panelis semi terlatih. Parameter uji meliputi warna, aroma dan rasa. Pengujian warna, aroma dan rasa dinilai pada serbuk yang sudah dilarutkan dengan cara melihat, membaui dan meminum produk. Cara penyajiannya yaitu dengan melarutkan 10 $\mathrm{gr} / 250 \mathrm{ml}$ air.

\section{Analisis Data}

Data yang diperoleh dianalisis dengan menggunakan analisis deskriptif persentase untuk mengetahui tingkat kesukaan panelis terhadap produk dan analisis varians (ANOVA) untuk melihat pengaruh perlakuan 
terhadap variabel yang diamati/diuji. Apabila ada pengaruh, dilanjutkan dengan uji BNT (Beda Nyata Terkecil) untuk mengetahui perbedaan di antara rata-rata perlakuan.

\section{HASIL DAN PEMBAHASAN}

Tingkat kesukaan panelis dilakukan untuk mengkaji reaksi panelis terhadap sampel yang diujikan yaitu diketahuinya daya terima panelis terhadap minuman serbuk berbasis lemon cui dengan cara analisis deskriptif persentase dapat dilihat pada Tabel 1.

Berdasarkan Tabel 1, tingkat kesukaan panelis berdasarkan indikator warna, aroma dan rasa minuman serbuk instan berbasis lemon cui, persentase tingkat kesukaan minuman serbuk instan berbasis lemon cui berkisar 57-67\%, dengan kriteria tingkat kesukaan adalah netral.

Tabel 1. Tingkat kesukaan panelis pada minuman serbuk instan berbasis lemon cui dengan penambahan sari pala dan cengkeh

\begin{tabular}{ccccc} 
Formulasi & Warna & Aroma & Rasa & (\%) \\
\hline A & $2,76^{\mathrm{a}}$ & $2,92^{\mathrm{b}}$ & 2,88 & 57 \\
B & $3.20^{\mathrm{c}}$ & $2,82^{\mathrm{a}}$ & 2,54 & 57 \\
C & $3,02^{\mathrm{b}}$ & $2,70^{\mathrm{a}}$ & 2,94 & 58 \\
D & $3,39^{\mathrm{e}}$ & $3,10^{\mathrm{bc}}$ & 3,12 & 64 \\
E & $3,68^{\mathrm{f}}$ & $3,12^{\mathrm{c}}$ & 3,24 & 67 \\
F & $3,32^{\mathrm{d}}$ & $2,96^{\mathrm{b}}$ & 3,14 & 63 \\
\hline
\end{tabular}

Ket. A. Sukrosa 50\% : Sari lemon cui 30\% : Air 20\%

B. Sukrosa $50 \%$ : Sari lemon cui $30 \%$ : Sari pala $0 \%$ : Sari cengkeh $20 \%$

C. Sukrosa 50\%: Sari lemon cui 30\% : Sari pala 5\% : Sari cengkeh $15 \%$

D. Sukrosa 50\% : Sari lemon cui 30\% : Sari pala 10\% : Sari cengkeh $10 \%$

E. Sukrosa 50\% : Sari lemon cui 30\% : Sari pala 15\%: Sari cengkeh 5\%

F. Sukrosa $50 \%$ : Sari lemon cui $30 \%$ : Sari pala 20\% : Sari cengkeh $0 \%$

Persentase dari tingkat kesukaan panelis terhadap minuman serbuk instan berbasis lemon cui maka menunjukkan bahwa semua formula dapat diterima dengan kriteria netral dari tingkat kesukaan yang diujikan. Tingkat kesukaan panelis berdasarkan indikator warna, aroma dan rasa minuman serbuk instan berbasis lemon cui dengan penambahan sari pala dan cengkeh yang paling disukai adalah formula $E$ dengan persentase 67\% (Tabel 1), namun minuman serbuk instan berbasis lemon cui yang disukai adalah formula B. Untuk lebih jelasnya berikut disajikan grafik radar (Gambar 1) tingkat kesukaan panelis terhadap minuman serbuk instan lemon cui.
Hasil uji organoleptik terhadap warna minuman serbuk instan lemon cui yaitu 2,763,68 . Warna produk yang disukai yaitu formula $\mathrm{E}$ (sari pala 15\%:sari cengkeh $5 \%$ ) yaitu mencapai 3,68. Warna minuman serbuk instan lemon cui yang paling disukai oleh panelis adalah warna kekuningan dan yang kurang disukai yaitu warna agak kuning dan kuning kecoklatan. Hal ini menunjukkan bahwa sedikit penambahan sari cengkeh (5\%) berkontribusi terhadap pembentukan warna kekuningan yang disukai oleh panelis. Terlihat bahwa semakin tinggi penilaian warna minuman serbuk instan lemon cui cenderung seiring berkurangnya konsentrasi sari cengkeh. Penentuan mutu suatu bahan 
pangan pada umumnya tergantung pada warna karena warna tampil lebih dahulu ${ }^{(7)}$.

Berdasarkan analisis varians penambahan sari pala dan cengkeh memberi pengaruh yang nyata terhadap warna dari minuman serbuk instan lemon cui $(p<0,05)$. Hal ini berhubungan dengan zat warna dari sari pala maupun cengkeh. Terlihat bahwa sari cengkeh membentuk warna kuning kecoklatan dibanding sari pala yang hanya membentuk warna kekuningan. Diduga bahwa sari cengkeh mengandung zat warna antosianin yang membuat warna minuman menjadi kuning

kecoklatan.

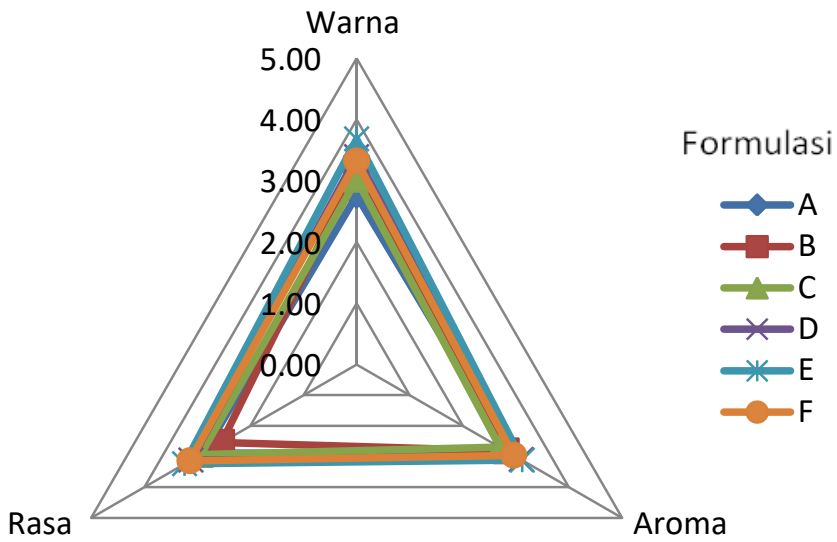

Gambar 1. Tingkat kesukaan panelis terhadap minuman serbuk instan berbasis lemon cui dengan penambahan sari pala dan cengkeh pada indikator warna, rasa dan aroma

Ket. (1) tidak suka, (2) kurang suka, (3) netral, (4) suka, (5) sangat suka

Antosianin merupakan kelompok zat warna berwarna kemerahan yang larut dalam air dan dapat dimanfaatkan sebagai pewarna makanan dan minuman. Antosianin adalah metabolit sekunder dari famili flavonoid, dalam jumlah besar ditemukan dalam buahbuahan dan sayur-sayuran ${ }^{(8)}$ yang secara alami, terakumulasi pada sel epidermis buahbuahan, akar, dan daun ${ }^{(9)}$. Hasil uji beda BNT $(\alpha=0.05 \%)$ pengaruh penambahan sari pala dan cengkeh terhadap minuman serbuk instan lemon cui memberi perbedaan yang nyata terhadap semua formula.

Berdasarkan pengujian organoleptik terhadap aroma minuman serbuk instan berbasis lemon cui dengan penambahan sari pala dan cengkeh yaitu 2,70-3,12. Aroma yang disukai yaitu formula $E$ (sari pala $15 \%$ : sari cengkeh 5\%) yaitu mencapai 3,12. Terlihat bahwa semakin tinggi konsentrasi sari pala cenderung membuat panelis menyukai. Hal ini dipengaruhi oleh aroma buah pala yang kuat. Aroma merupakan zat volatil yang dilepaskan dari produk atau aroma seringkali disebut sebagai bau dari bahan pangan ${ }^{(7)}$. Hasil analisis varians penambahan sari pala dan cengkeh memberi pengaruh yang nyata terhadap aroma dari minuman serbuk $(p<0,05)$. Hal ini menunjukkan bahwa sari pala maupun cengkeh mengandung aroma sehingga dapat meningkatkan aroma dibanding 
kontrol. Aroma sari pala lebih menonjol dibanding aroma sari daun cengkeh. Hal ini juga berhubungan dengan konsentrasi sari pala yang lebih tinggi dari daun cengkeh. Daging buah pala mengandung senyawa aromatik yaitu aromatic ether (myristicin, elemicin dan safrole) $)^{(5)}$. Aroma buah pala yang khas berasal dari komponen-komponen kimiawi yang terkandung di dalamnya seperti monoterpen hidrokarbon dan monoterpen alkohol, sedangkan komponen aroma utama adalah terpen, terpene alcohol dan fenolik eter ${ }^{(10)}$. Hasil BNT ( $\left.\alpha=0.05 \%\right)$ pengaruh penambahan sari pala dan sari cengkeh terhadap minuman serbuk lemon cui menunjukkan formula $(A, D, F)$, formula $(B$, C) serta formula $(D, E)$ menunjukkan perbedaan yang tidak nyata. Perbedaan yang tidak nyata menunjukkan kecenderungan bau yang sama yaitu penambahan sari pala/cengkeh pada formula-formula tersebut cenderung secara kuantitatif hampir sama.

Hasil uji organoleptik terhadap rasa minuman serbuk instan berbasis lemon cui dengan penambahan sari pala dan cengkeh yaitu 2.54-3.24. Rasa minuman serbuk instan yang disukai yaitu formula $E$ (sari pala $15 \%$ : sari cengkeh $5 \%$ ) yaitu mencapai 3,24. Terlihat bahwa semakin tinggi konsentrasi sari pala cenderung membuat panelis suka. Hal ini diduga karena aroma dari sari pala. Rasa sangat berhubungan dengan aroma, di mana keduanya merupakan komponen cita rasa. Jika aroma disukai biasanya rasa juga akan disukai. Terlihat pada persentase produk yang paling disukai oleh panelis sejalan antara aroma dan rasa. Senyawa cita-rasa pada produk dapat memberikan rangsangan pada indera penerima. Berdasarkan analisis varians penambahan sari pala dan cengkeh tidak memberi pengaruh terhadap rasa dari minuman serbuk instan lemon cui. Hal ini menunjukkan bahwa rasa dari tiap formula cenderung hampir sama.

\section{KESIMPULAN}

Berdasarkan hasil penelitian maka diperoleh simpulan bahwat tingkat kesukaan panelis terhadap minuman serbuk instan berbasis lemon cui yang terbaik adalah formula B.

\section{DAFTAR PUSTAKA}

1. Rorong JA. Uji aktivitas antioksidan dari daun cengkeh (Eugenia carryophyllus) dengan metode DPPH. J Chem. 2008;Vol. 1, No. 2

2. Paulus. Lemon Cui sebagai Tanaman Maskot Kota Manado. 2013. Available from: http://sulutiptek.com/lemon-cui-php.php. Diakses pada tanggal 23 September 2013.

3. Prihastuti D dkk. Analisis karakteristik antioksidan dalam mister kumis: Minuman instan serbuk kulit manggis (Gracinia mangostana L). Universitas Negeri Yogyakarta. 2014.

4. Suryanto $E$ dkk. Potensi senyawa polifenol antioksidan dari pisang goroho (Musa spp). Agritech 31:289-296. 2011.

5. Rismunandar. Budidaya dan Tataniaga Pala. Jakarta. 1990.

6. Ramadina. Pengaruh penggunaan jumlah gula terhadap karakteristik sirsak (Annona muricata). Universitas Negeri Semarang; 2013.

7. Winarno F. Kimia Pangan dan Gizi. PT. Gramedia. Jakarta. 2002.

8. Supriyono T. Kandungan B-karoten, polifenol total dan aktivitas "merantas" radikal bebas kefir susu kacang hijau oleh pengaruh starter (L. bulgaris dan Candida kefir) dan konsentrasi glukosa. Universitas Diponegoro. Semarang. 2008.

9. Sundari U. Uji banding metode ekstraksi karaktenoid dan tokoferol sari buah merah. Institut Pertanian Bogor. Bogor. 2008.

10. Arief RW. Potensi pengolahan daging pala menjadi aneka produk olahan bernilai ekonomi tinggi. Bul. Littro. 2015;26(165-173). 